www.nature.com/pj

\title{
Impact modification of a PET-PBT blend using different impact modifiers
}

\author{
Rashmi Nitin Baxi ${ }^{1}$, Shailkumar Umakant Pathak ${ }^{2}$ and Dilip Ramkrishna Peshwe ${ }^{2}$ \\ The performance enhancement of poly(ethylene terephthalate) (PET) and poly(butylene terephthalate) (PBT) blends using \\ different impact modifiers was studied using various analytical tools. A comparison of the obtained impact resistance data was \\ performed. A significant increase in toughness using 10\% Elvaloy AC in a 60-40 PET and PBT blend was observed. In addition, \\ a good combination of tensile strength and impact strength was observed in the 60-40 PET and PBT blend using polypropylene \\ co-polymer B220 MN as an impact modifier. An attempt was also been made to investigate the chemical formulations of the \\ constituent materials and the newly formed blends using the qualitative technique of Fourier transformed infrared studies. \\ The results of the mechanical studies of the newly formed blends were also correlated with those of the morphological, \\ structural and thermal analysis performed in the present investigation.
}

Polymer Journal (2011) 43, 801-808; doi:10.1038/pj.2011.69; published online 3 August 2011

Keywords: impact modification; PBT; PET

\section{INTRODUCTION}

Toughened polymeric materials are receiving considerable attention. The role of this important group of additives is to improve impact strength, with the aim of overcoming inherent brittleness and improving the notch sensitivity of low-cost components with inferior properties. The key requirement of the impact modifier is the ability to bind chemically or mechanically with the matrix polymer. Studies on basic poly(ethylene terephthalate) (PET)-poly(butylene terephthalate) (PBT) blends have been carried out by various researchers in the last few decades. The theoretical compatibility of a 70/30 PET/PBT blend was established earlier by Mishra et al. ${ }^{1}$ PET-PBT blends were studied by Aravinthan et al. ${ }^{2}$ across almost their entire compositional range. The miscibility, rheology, structure and some mechanical features of these blends were reported by Aravinthan et al. This study suggests that the constituents of the blends are miscible and also that the properties are dependent on composition. The establishment of miscibility in other aryl resin materials, such as PET/ poly(trimethylene terephthalate), belonging to the family of polyesters was carried out by Supaphol, ${ }^{3}$ and PBT/poly(trimethylene terephthalate) was studied by Kuo et al. ${ }^{4}$ and Dabgseetyb. ${ }^{5}$ These studies suggest a possible interaction between the constituents, which obey the Gordon-Taylor and Fox equations. These are the robust mathematical models of polymer solution thermodynamics. In addition to binary blends of polyesters, quaternary blends of PET/poly(trimethylene terephthalate)/PBT and PEI have been studied by Woo et al. ${ }^{6}$ The reported glass transition temperatures of these blends agree well with the Gordon-Taylor equation for this quaternary system. With respect to the impact modification of polyesters, the deformation behavior of PET, PBT and PBT based thermoplastic elastomers has been studied by Stribeck et al. ${ }^{7}$ Small angle X-ray scattering studies and the observed small angle X-ray scattering patterns indicate an increase in chain flexibility from ethylene glycol for PET to TMG tetra-methylene glycol for PBT. Chaudhari et al. ${ }^{8}$ studied the impact modification of PET (recycled) using polyolefinic elastomer and reported a significant improvement in the impact strength of PET along with an improvement in percent elongation. The contribution of interfacial modification to the impact behavior of PET-polyolefin grafted maleic anhydride elastomer blends was studied by Chiu et al. ${ }^{9}$ They stated that with the increase in polyolefin grafted maleic anhydride content, significant improvement in the notched izod impact strength was observed. Loyens et al. ${ }^{10}$ studied an important toughening mechanism involving rubber toughened semicrystalline PET. This mechanism results in cavitations in the triaxial stress state ahead of a crack tip and produces dilatation, which in turn is responsible for void formation in the particle or particle-matrix interface. This is responsible for the dampening effect. A steep increase in the volume strain upon tensile loading confirmed the presence of a rubber voiding mechanism in PET/(EPR/E-GMA8) blends. In a developmental study on PET-PBT blend materials, different blended systems across the entire compositional range were synthesized and characterized in our pilot experimentation. To ascertain miscibility, the materials' mechanical, microstructural and bulk structural properties were evaluated. The results were consistent with those of earlier ${ }^{2}$ related studies. Across the entire compositional range, the 60/40 PET/PBT blend

${ }^{1}$ Mechanical Engineering Department, GHR College of Engineering, Digdoh Hills, Nagpur, Maharashtra, India and ${ }^{2}$ Metallurgical and Materials Engineering Department, Visvesvaraya National Institute of Technology, Nagpur, Maharashtra, India

Correspondence: Dr RN Baxi, Mechanical Engineering Department, GHR College of Engineering, CRPF, Gate no.3, Digdoh Hills, Hingna Road, Nagpur, Maharashtra 440016, India. E-mail: r_baxi@yahoo.com

Received 8 March 2011; revised 18 May 2011; accepted 23 May 2011; published online 3 August 2011 
labeled the D blend exhibited lower impact strength. ${ }^{11}$ The modification of the PET-PBT blend so as to improve its impact strength and develop a scientific correlation between its properties was the aim of the proposed experimentation. Notably, studies related to the modification of PET-PBT (60-40) blends have not yet been reported in the literature.

\section{EXPERIMENTAL PROCEDURE}

\section{Materials}

Commercial grade PET was supplied by ASPET edge (South Asian Petrochem Limited, Kolkata, India) with IV $0.8 \pm 0.02 \mathrm{dlg}^{-1}$. PBT ultradur B 2550 grade with viscosity number $107 \mathrm{~cm}^{3} \mathrm{~g}^{-1}\left(1.07 \mathrm{dl} \mathrm{g}^{-1}\right)$ was supplied by BASF Ultradur (Mumbai, India). Elvaloy 1224AC was supplied by Dupont Industrial Polymers (Shanghai, China). PP-cp with grade Repol B220MN was supplied by Reliance Industries Limited (Mumbai, India).

\section{Blends}

Samples using PET and PBT were prepared as per the compositional details mentioned in Table 1. Sample D was prepared using pristine resins with a blend ratio 60 PET/40 PBT. Elvaloy AC and PP-cp were used for impact modification of the D blend. Samples of all blends were prepared by melt extrusion using a single screw extruder. The constituent materials were thoroughly mixed and dried at $110^{\circ} \mathrm{C}$ for $4 \mathrm{~h}$ in an air circulating oven before melt extrusion. The temperature profiles maintained during extrusion were zone $1: 200{ }^{\circ} \mathrm{C}$, zone 2:230 ${ }^{\circ} \mathrm{C}$, zone $3: 250{ }^{\circ} \mathrm{C}$ and $260^{\circ} \mathrm{C}$ for the die zone. The screw speed was maintained at 40 r.p.m.

The extrudates were water cooled and palletized. These pallets were again dried before injection molding in the air circulating ovens at $110^{\circ} \mathrm{C}$ for $3 \mathrm{~h}$. Standard American Society of Testing and Materials tensile and impact samples were molded using an Omega 80A 80W, Ferromatic Milacron, Gujarat, India, hydraulic injection molding machine. The temperature profiles were 220, 220, $240,265^{\circ} \mathrm{C}$ for zone 1 , zone 2 , zone 3 and for the nozzle zone, respectively.

\section{Analytical methods}

Mechanical characterization. The tensile strength at yield at $23{ }^{\circ} \mathrm{C}$ and elongation at break were measured using a universal tensile testing machine (8502/Instron, Chennai, India) as per American Society of Testing and Materials D638. The cross-head speed maintained was $50 \mathrm{~mm} \mathrm{~min}^{-1}$.

The izod pendulum impact resistance of the blends was measured using a standard pendulum type hammer mounted on a standard machine (International Engineering Industries, Mumbai, India) as per American Society of Testing and Materials D 256. A micrometer-operated notch cutter was used to cut a standard ' $\mathrm{V}$ ' notch. The average value of the five readings is reported in this work.

Thermal characterization. Differential scanning calorimetry was used to determine qualitative and quantitative information about physical and chemical changes that involve endothermic or exothermic processes or changes in the heat capacity of the sample. The melting and crystallization and related thermal studies of the blend were performed using differential scanning calorimetry (9PT24 M/Mettler Toledo, Powai, Mumbai). The scan procedure followed for thermal analysis performed by heating the sample from 25 to $260^{\circ} \mathrm{C}$ at a rate of $10^{\circ} \mathrm{C} \mathrm{min}-1$ followed by quenching and reheating at the same rate up to $260{ }^{\circ} \mathrm{C}$ during the second scan.

\section{Table 1 Impact modified blends and their composition}

\begin{tabular}{lcc}
\hline S. no. & Blend & Composition \\
\hline 1 & $\mathrm{~K}$ & $2 \%$ ELVALOY AC in D \\
2 & $\mathrm{~L}$ & $10 \%$ ELVALOY AC in D \\
3 & $\mathrm{~N}$ & $2 \%$ PP-Cp B220 MN in D \\
4 & $\mathrm{P}$ & $10 \%$ PP-Cp B220 MN in D \\
\hline
\end{tabular}

Morphological characterization. Scanning electron microscopy (SEM) was carried out using a 6380A/Jeol (Tokyo, Japan). Samples were fractured under cryogenic conditions for microstructural examination. Samples were observed after platinum coating before installation in the SEM chamber.

FTIR studies. Qualitative chemical analysis and the identification of functional groups in the blend sample were performed using a Perkin Elmer FTIR instrument (Perkin Elmer, Waltham, MA, USA). Solid sample material was used for FTIR studies of the blend.

$X$-ray diffraction studies. The crystallinity of the blend materials was evaluated using a PANalytical X ray diffractometer (Amlelo, The Netherlands) with a copper anode using $\mathrm{K} \propto$ radiation. The X-ray diffraction of the blends and pure materials was recorded at room temperature over a range of $2 \theta$ from $0^{\circ}$ to $60^{\circ}$ using a step size of $0.01^{\circ}$.

\section{RESULTS AND DISCUSSION}

\section{Mechanical properties}

The mechanical properties of the constituent materials ${ }^{11}$ and the modified blends are shown in Table 2.

The addition of $2 \%$ Elvaloy AC in the D blend slightly lowers the tensile strength of the modified $\mathrm{K}$ blend, whereas impact strength is improved by $27 \%$. Further increase in the modifier content to $10 \%$ in the D blend improves the impact strength by $163 \%$ in the L blend, which is the highest value of impact strength recorded for the L blend.

The addition of 2\% PP-cp BMN220 improves the impact strength of the D blend by about $75 \%$, which is comparatively lower (by about $50 \%)$ than the impact modification due to Elvaloy AC. With the increase in the PP-cp BMN220 content to $10 \%$, the impact strength remains almost the same as that of the $\mathrm{N}$ blend. Higher percent elongation at break is observed in impact-modified blends than in the constituent material of the D blend. All of the impact-modified blends are semicrystalline in nature as observed from X-ray diffraction diffractographs. (The structural behavior of these blends is discussed in detail in section Morphological properties.) The crystalline region of the impact-modified blends may act as a reinforcement to enhance the percent elongation. Moreover, the amorphous portion of the semicrystalline polymer might have behaved similar to a rubbery phase to contribute a higher impact strength coupled with a slightly improved percent elongation. ${ }^{12}$

The addition of 10\% impact modifier (both Elvaloy AC and PP-cp) significantly lowers the universal tensile strength by about $20 \%$. Modification of the segmental structure, either in the form of branching or cross-linking, might have been responsible for lowering the universal tensile strength. ${ }^{13}$ Graphical representations of variations in the tensile strength and impact strength of the constituent materials and the blended systems are shown in Figures 1 and 2, respectively.

Both crazing and shear yielding involves the absorption of energy throughout a large volume of material other than just at the crack tip, ${ }^{14}$ and this phenomenon must have occurred in these formulated blends during impact loading.

Table 2 Mechanical properties of the modified blends and their constituent materials

\begin{tabular}{lcccccccc}
\hline & Elvaloy & $P P-c p$ & & & & & \\
Property & $C 1224$ & $220 \mathrm{MN}$ & $D$ & $K$ & $L$ & $N$ & $P$ \\
\hline Ultimate tensile strength (MPa) & $>46$ & 24 & 57 & 55 & 45 & 52 & 46 \\
Elongation at break (\%) & $>48$ & 53 & 6 & 8.2 & 8.9 & 10.1 & 7.9 \\
Izod impact strength $\left(\mathrm{J} \mathrm{m}^{-1}\right)$ & $>108$ & 93 & 33 & 42 & 87 & 53 & 55
\end{tabular}




\section{Morphological properties}

The fine and uniform lamellar microstructure of the D blend is shown in Figure 3. SEM photomicrographs of the $\mathrm{K}$ and $\mathrm{L}$ blends modified using Elvaloy AC and N and P blends modified using PP-cp indicates immiscibility as shown in Figure 3. Co-continuity of the structure is shown in the microphotograph of the L blend, which indicates the network formation of the dispersed phase. The reinforcing effect of the material having high impact strength might have enhanced the properties. It can be stated that to obtain co-continuity of the phase structure, the optimum weight percent of the impact modifier Elvaloy

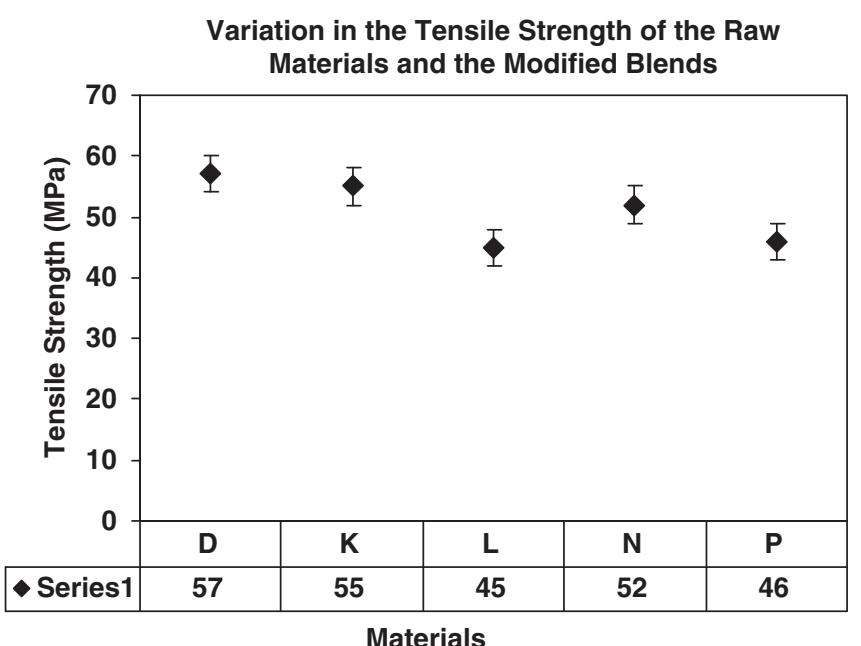

Figure 1 Variation in the tensile strengths of the constituent materials and impact modified blends. A full color version of this figure is available at Polymer Journal online.

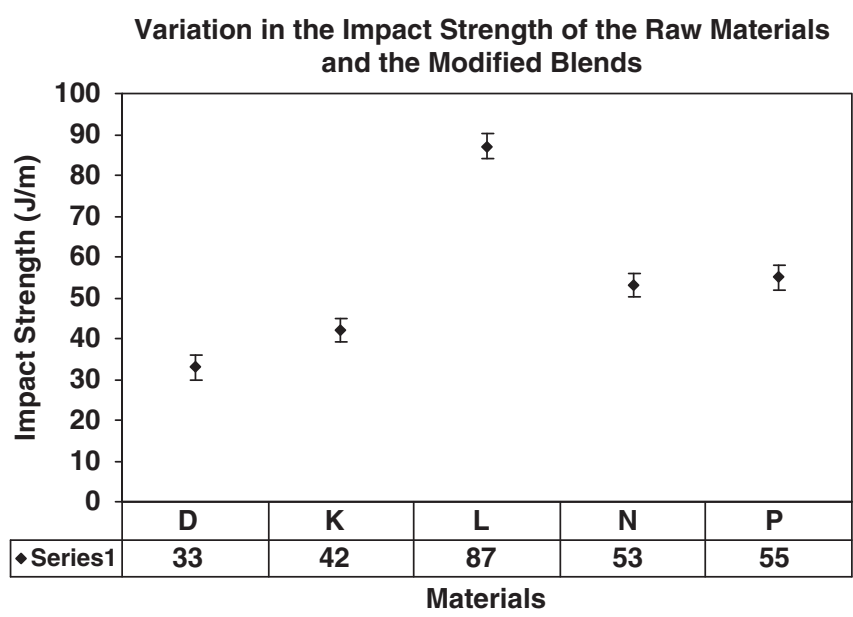

Figure 2 Variation in the impact strengths of the constituent materials and impact modified blends. A full color version of this figure is available at Polymer Journal online.

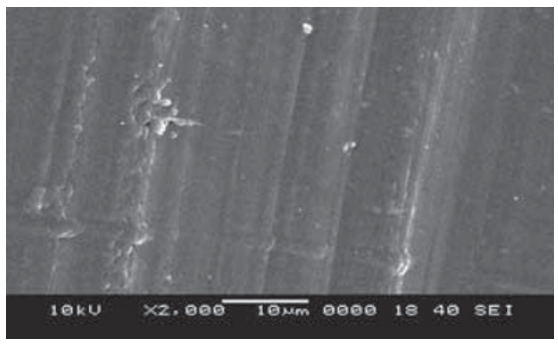

D Blend

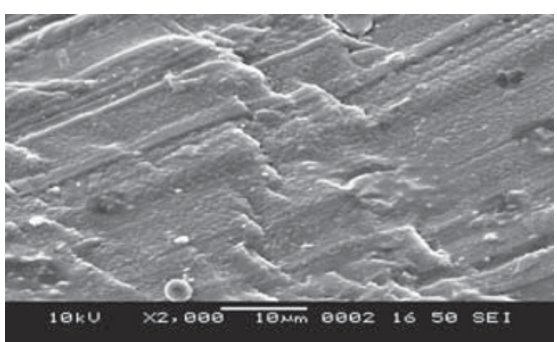

K Blend

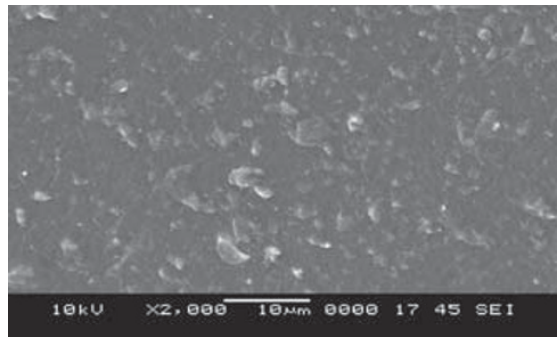

N Blend

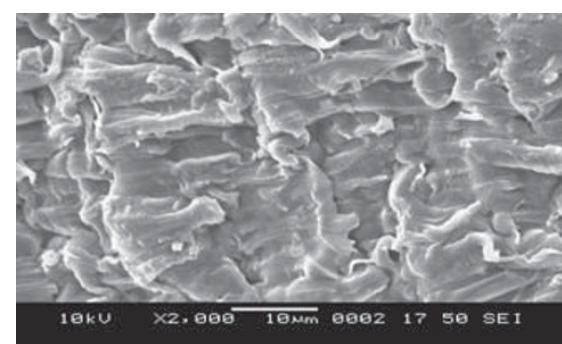

L Blend

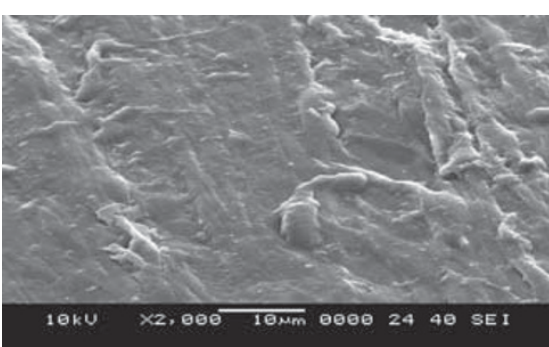

P Blend

Figure 3 Microphotographs of the constituent blend and the modified blends. 
AC should be a maximum of up to $10 \%$ of the total weight of the blend. Similar morphological features indicating co-continuity and network formation of the phases of the impact modified blends were reported in the study of Paul et al. ${ }^{15}$ It was also observed in this study that blends showing this type of morphology exhibited the highest impact strength. The ductile fracture of the thermoplastics can also be attributed to the presence of smaller threads with thickenings at the end. The stretching of a macromolecule followed by its rupture causes it to recoil similar to a spring. This effect is pronounced at highly stressed fracture sites and produces nodular thickening at the end of macromolecules. ${ }^{16}$ A similar morphology is observed in SEM studies of $\mathrm{N}$ and $\mathrm{P}$ blends.

\section{X-ray diffraction studies of impact modified blends}

The D blend is amorphous in nature. ${ }^{11}$ However, the appearance of both sharp and diffuse diffraction peaks in the X-ray diffraction pattern of the remaining modified blends supports the existence of crystalline domains between amorphous regions. The semicrystalline nature of the modified blends is shown in Figure 4. The crystallinity of the constituent materials and the extent of crystallinity induced in modified blends are reported in Table 3.

It was observed that the crystallinity of the Elvaloy AC is $25 \%$ and the addition of $2 \%$ Elvaloy $\mathrm{AC}$ in the $\mathrm{K}$ blend and $10 \%$ Elvaloy $\mathrm{AC}$ in the L blend induces $16 \%$ and $19 \%$ crystallinity, respectively, in these modified blends. The crystallinity of the $\mathrm{K}$ and $\mathrm{L}$ blends was found to be about $15-25 \%$ lower than that of its crystalline constituent Elvaloy AC. Blend L consists of $81 \%$ amorphous domain in its structure. Copolymerization might have reduced the linearity of the molecular structure, and, thus, the highest impact strength of L blend can be correlated with this asymmetrical branched molecular structure. ${ }^{17}$ The observed crystallinity value of PP-cp is $60 \%$ and the addition of $2 \%$

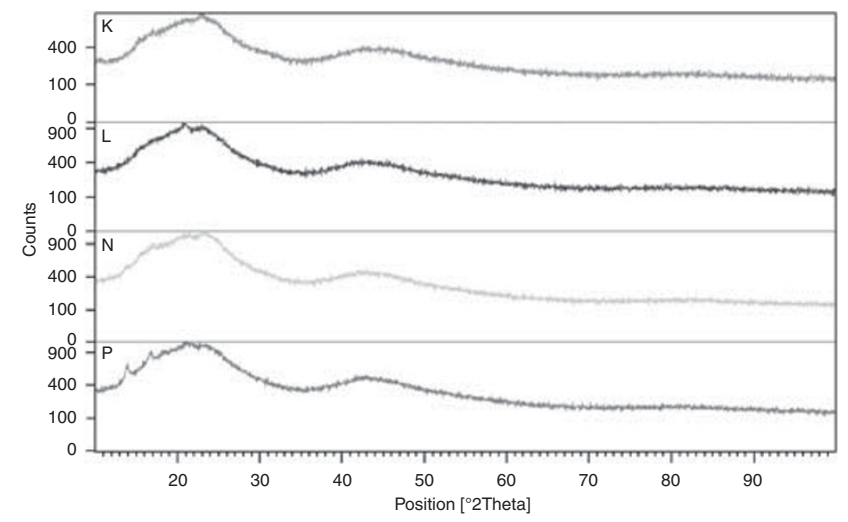

Figure 4 X-ray diffractographs of impact modified blends. A full color version of this figure is available at Polymer Journal online.

Table $3 \%$ Crystallinity of the constituent resins and impact modified blends

\begin{tabular}{lcc}
\hline S. no. & Modified blends and constituent materials & \% Crystallinity \\
\hline 1 & D & - \\
2 & K & 16 \\
3 & L & 19 \\
4 & N & 6 \\
5 & P & 10 \\
6 & Elvaloy AC & 25 \\
7 & PP-cp & 60 \\
\hline
\end{tabular}

PP-cp to the $\mathrm{N}$ blend and 10\% PP-cp to the P blend produces a gradual increase in crystallinity. For the same amount of added impact modifiers Elvaloy AC and PP-cp used to modify the D blend, higher crystallinity was observed in the blends featuring Elvaloy AC.

The addition of $2 \%$ Elvaloy to the D blend shifts the peak at $20.96^{\circ}$ to a slightly lower angle of $20^{\circ}$, whereas the peak at $21.9^{\circ}$ is not observed in the $\mathrm{K}$ blend, and entirely new peaks at $23^{\circ}$ and $24.8^{\circ}$ appear (Table 4). Structural modification due to the addition of a highly polar modifier is evidenced by this result. A similar shift in the peak position from $20.96^{\circ}$ to $20.8^{\circ}$ was observed for the $\mathrm{L}$ blend, and an additional peak at $23^{\circ}$, the same position as that of the $\mathrm{K}$ blend, is observed in the $\mathrm{L}$ blend. The nucleating effect of the impact modifiers is evidenced from the reported data. ${ }^{18}$ The parent peaks of PP-cp show well resolved peaks at $13.66^{\circ}, 16.46^{\circ}$ and $18.1^{\circ}$. The $\mathrm{N}$ blend modified with $2 \%$ PP-cp exhibited only one peak at $17^{\circ}$, whereas the modified P blend showed two peaks at $13.9^{\circ}$ and $16.74^{\circ}$. These results indicate a positive shift in the peak position with respect to the parent peaks of PP-cp.

The crystallite size of the impact modifier and the crystalline phases of the modified blends were calculated using the Scherrer equation. The average crystallite size of the Elvaloy AC is reported to be 0.339 and $0.132 \mu \mathrm{m}$ for PP-cp (Table 3). The crystallite sizes of the blends featuring Elvaloy AC are lower than those of PP-cp. These results suggest the fragmentation and dispersion of these modifiers during processing. Minor variation in the crystallite size of the $\mathrm{K}$ and $\mathrm{L}$ blends using Elvaloy $\mathrm{AC}$ and $\mathrm{N}$ and $\mathrm{P}$ blends using PP-cp was also observed.

\section{FTIR studies of impact modified blends}

The infrared (IR) spectra of the modified blends, where the peak position is plotted versus the percent transmittance, is shown in Figure 5.

The sharp peaks at 2848 and at $2916 \mathrm{~cm}^{-1}$ in Elvaloy AC (Table 5) can be attributed to $\mathrm{C}-\mathrm{H}$ stretching. $\alpha$-, $\beta$-unsaturated esters show $\mathrm{C}=\mathrm{O}$ vibration in the region between 1715 and $1735 \mathrm{~cm}^{-1}$, which is confirmed by the presence of a peak at $1736 \mathrm{~cm}^{-1}$. Peaks at 1463 and $1376 \mathrm{~cm}^{-1}$ are identified in the spectrograph as $\mathrm{C}-\mathrm{H}$ bending and C-H deformation of methylene, respectively. The peak at $719 \mathrm{~cm}^{-1}$ can be attributed to methylene rocking. The FTIR results indicate the presence of methyl acrylate in Elvaloy AC. The addition of 2\% Elvaloy $\mathrm{AC}$ to the $\mathrm{D}$ blend indicates some deviation in the IR spectra from that

Table 4 X-ray diffraction peak positions of the constituent materials and impact modified blends

\begin{tabular}{|c|c|c|c|c|}
\hline S. no. & $\begin{array}{l}\text { Constituent materials } \\
\text { and modified blends }\end{array}$ & $\begin{array}{c}\text { Peak } \\
\text { position (20) }\end{array}$ & $\begin{array}{l}\text { Crystallite } \\
\text { size }(\mu \mathrm{m})\end{array}$ & $\begin{array}{c}\text { Average crystallite } \\
\text { size }(\mu m)\end{array}$ \\
\hline 1 & D blend & - & - & - \\
\hline 2 & Elvaloy $\mathrm{AC}$ & $\begin{array}{l}20.96^{\circ} \\
21.19^{\circ}\end{array}$ & $\begin{array}{l}0.396 \\
0.283\end{array}$ & 0.339 \\
\hline 3 & PP-cp & $\begin{array}{c}16.46^{\circ} \\
13.66^{\circ} \\
18.1^{\circ}\end{array}$ & $\begin{array}{l}0.178 \\
0.196 \\
0.123\end{array}$ & 0.132 \\
\hline 4 & K & $\begin{array}{c}20^{\circ} \\
23^{\circ} \\
24.8^{\circ}\end{array}$ & $\begin{array}{l}8.1 \\
8.4 \\
8.3\end{array}$ & 8.3 \\
\hline 5 & $\mathrm{~L}$ & $\begin{array}{c}20.8^{\circ} \\
23^{\circ}\end{array}$ & $\begin{array}{l}9.9 \\
7.1\end{array}$ & 8.5 \\
\hline 6 & $\mathrm{~N}$ & $17^{\circ}$ & 9.9 & 9.9 \\
\hline 7 & $P$ & $\begin{array}{c}13.9^{\circ} \\
16.74^{\circ}\end{array}$ & $\begin{array}{l}10.6 \\
10.4\end{array}$ & 10.5 \\
\hline
\end{tabular}


of the D blend (Table 6). The $\mathrm{C}-\mathrm{C}$ stretching vibration at $1103 \mathrm{~cm}^{-1}$ in the D blend is shifted to $1090 \mathrm{~cm}^{-1}$. Similarly, additional peaks at 872,1207 and $1236 \mathrm{~cm}^{-1}$ in the region of the $\mathrm{C}-\mathrm{C}$ stretch vibration are observed in the modified $\mathrm{K}$ blend. The positive shift from 1266 to $1288 \mathrm{~cm}^{-1}$ in this range for the $\mathrm{C}-\mathrm{C}$ stretching vibration is also observed in the modified ' $\mathrm{K}$ ' blend. A minor change in the $\mathrm{C}-\mathrm{O}$ stretching vibration of the ester from 1356 to $1341 \mathrm{~cm}^{-1}$ is observed in the $\mathrm{K}$ blend, and an entirely new peak at $1388 \mathrm{~cm}^{-1}$ is observed in this range. Most of the bands for $\mathrm{C}=\mathrm{C}$ aromatic stretching remains unchanged in the modified blend, except for a negative shift from 1454

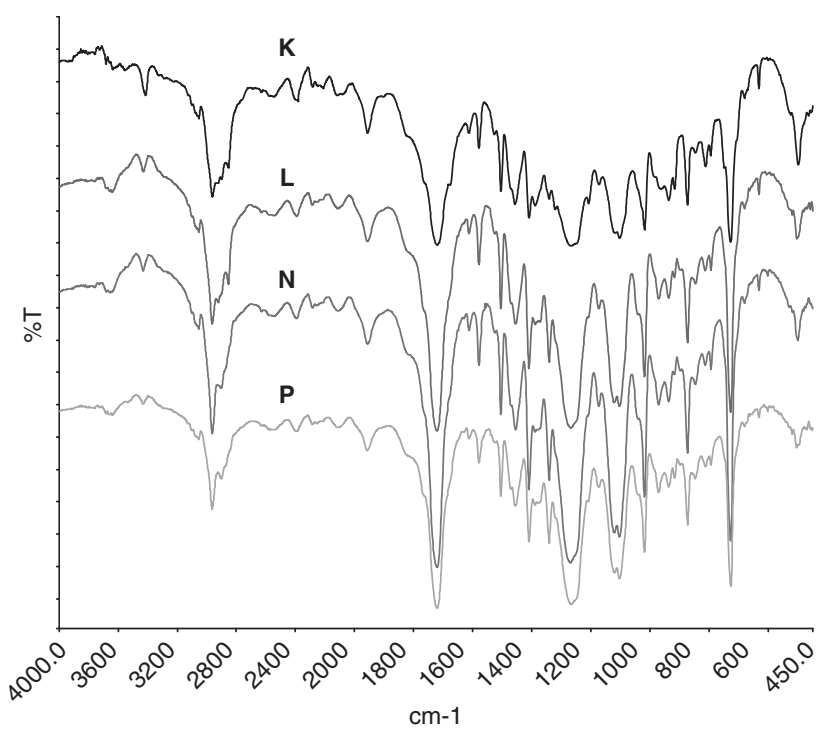

Figure 5 FTIR bands of impact modified blends. A full color version of this figure is available at Polymer Journal online. to $1447 \mathrm{~cm}^{-1}$. A negative shift in the case of the most characteristic $\mathrm{C}=\mathrm{O}$ vibration of the ester is observed from 1720 to $1709 \mathrm{~cm}^{-1}$ because of internal conjugation. Extra peaks at 2282 and $2380 \mathrm{~cm}^{-1}$ are also observed in this region for the modified blended system. Shifting of the peak corresponding to $\mathrm{C}-\mathrm{H}$ aliphatic stretching in the negative direction from 2905 to $2869 \mathrm{~cm}^{-1}$ is observed. Some complexity and modification in the structure, especially at the highly polar sites (COO) of the acrylate, are predicted from these results.

At a higher concentration of the impact modifier (10\%) in the $\mathrm{L}$ blend, the intensity of the peaks further increases. For the characteristic C-C stretching mode, an additional peak at $1260 \mathrm{~cm}^{-1}$ in the form of shoulder of the parent peak $1271 \mathrm{~cm}^{-1}$ was observed. Two additional peaks at 1380 and $1420 \mathrm{~cm}^{-1}$ in the spectral region between 1350 and $1450 \mathrm{~cm}^{-1}$ are also noticed in the modified $\mathrm{L}$ blend. The peak position corresponding to $1420 \mathrm{~cm}^{-1}$ is absent in $\mathrm{K}$ the blend, which indicates further modification of the structure at higher concentrations of the impact modifier; this might be related to observed enhancement in mechanical properties. IR bands corresponding to aromatic $\mathrm{C}=\mathrm{C}$ stretching, $\mathrm{C}=\mathrm{O}$ stretching of ester, $\mathrm{C}-\mathrm{H}$ aromatic stretching and $\mathrm{C}-\mathrm{H}$ aliphatic stretching are located in the spectra of the 'L' blend with minor shifts in their positions with respect to those of the $\mathrm{K}$ blend.

The co-polymer moiety of PP-cp is not disclosed in the technical data sheet of PP-cp B $220 \mathrm{MN}$. The IR spectrograph of B220MN PPcp shows strong peaks at 2913 and at $2837 \mathrm{~cm}^{-1}$. These peak positions were reported as a spectral feature of EPDM. Hence, it can be inferred from these results that B220 MN may be the co-polymer of EPDM. The enhancement in the impact characteristics supports this assumption. The spectral position $721 \mathrm{~cm}^{-1}$ corresponds to $\mathrm{C}-\mathrm{H}$ rocking; this bending (rocking) motion is associated with four or more $\mathrm{CH}_{2}$ groups in the open chain commonly known as the long chain band, whereas the peak at $1376 \mathrm{~cm}^{-1}$ indicates $\mathrm{C}-\mathrm{H}$ bending of the methyl pendent group of the polypropylene moiety. The addition of $2 \%$ PP-cp B 220

Table 5 Infrared spectral position of constituent materials

\begin{tabular}{|c|c|c|c|c|c|}
\hline \multicolumn{2}{|c|}{ Infrared blend $D$ wave numbers $\left(\mathrm{cm}^{-1}\right)$} & \multicolumn{2}{|c|}{ Elvaloy $A C$ wave numbers $\left(\mathrm{cm}^{-1}\right)$} & \multicolumn{2}{|r|}{ PP-cp B 220MN wave numbers $\left(\mathrm{cm}^{-1}\right)$} \\
\hline 727 & Benzene ring (di substitution and $\mathrm{C}-\mathrm{H}$ rocking) & 719 & $\mathrm{C}-\mathrm{H}$ rocking & 721 & $\mathrm{C}-\mathrm{H}$ rocking \\
\hline 894 & C-C stretch $\left(800-300 \mathrm{~m}^{-1}\right)$ & 821 & C-C stretch $\left(800-1300 \mathrm{~cm}^{-1}\right)$ & 808 & C-C stretch $\left(800-1300 \mathrm{~cm}^{-1}\right)$ \\
\hline 917 & & 1017 & & 841 & \\
\hline 937 & & 1160 & & 973 & \\
\hline 1019 & & 1194 & & 998 & \\
\hline 1103 & & 1376 & $\mathrm{C}-\mathrm{H}$ bending (methyl) & 1167 & \\
\hline 1173 & & 1463 & $\mathrm{C}-\mathrm{H}$ def. (methyl) & 1256 & \\
\hline 1266 & & 1736 & $\mathrm{C}=\mathrm{O}$ stretch (acrylate) & 1376 & $\mathrm{C}-\mathrm{H}$ bending (methyl, $\mathrm{CH}_{3}$ ) \\
\hline 1356 & $\mathrm{C}-\mathrm{O}$ stretching ester & 2848 & C-H stretch aliphatic & 1387 & \\
\hline \multicolumn{6}{|l|}{1387} \\
\hline & & 2916 & & 1410 & \\
\hline 1409 & & & & 1431 & \\
\hline 1454 & $\mathrm{C}=\mathrm{C}$ stretch aromatic $\left(1450-1650 \mathrm{~cm}^{-1}\right)$ & & & 1455 & Methylene $\left(\mathrm{CH}_{2}\right.$ bending) \\
\hline 1505 & & & & 1610 & $\mathrm{C}=\mathrm{C}$ stretch \\
\hline 1524 & & & & 1645 & \\
\hline 1578 & & & & 2837 & EPDM spectral feature \\
\hline 1613 & & & & 2852 & C-H stretch aliphatic $\left(2850-2960 \mathrm{~cm}^{-1}\right)$ \\
\hline 1720 & $C=0$ stretch ester $\left(1715-1730 \mathrm{~cm}^{-1}\right)$ & & & 2913 & \\
\hline 1956 & & & & 2950 & \\
\hline \multicolumn{6}{|l|}{2543} \\
\hline 2905 & C-H stretch aliphatic $\left(2850-2960 \mathrm{~cm}^{-1}\right)$ & & & & \\
\hline \multicolumn{6}{|c|}{ 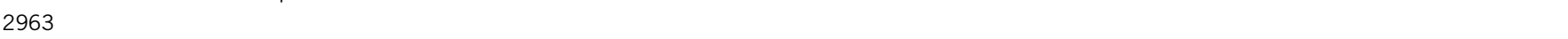 } \\
\hline 3054 & C-H stretch aromatic $\left(3000-3050 \mathrm{~cm}^{-1}\right)$ & & & & \\
\hline
\end{tabular}


Table 6 Infrared spectral positions of the modified blends

\begin{tabular}{|c|c|c|c|c|c|}
\hline & $K$ blend $\left(\mathrm{cm}^{-1}\right)$ & $L$ blend $\left(\mathrm{cm}^{-1}\right)$ & & $N$ blend $\left(\mathrm{cm}^{-1}\right)$ & $P$ blend $\left(\mathrm{cm}^{-1}\right)$ \\
\hline Benzene ring (di substitution) & 793 & & & 793 & \\
\hline \multirow{5}{*}{ C-C stretch $\left(800-1300 \mathrm{~cm}^{-1}\right)$} & 1015 & 1016 & & 1015 & 1016 \\
\hline & 1090 & 1091 & & 1091 & 1092 \\
\hline & 1207 & 1213 & & 1236 & 1238 \\
\hline & & 1271 & & 1407 & 1408 \\
\hline & 1288 & & & & 1430 \\
\hline \multirow[t]{3}{*}{$\mathrm{C}-\mathrm{O}$ stretching ester } & 1341 & 1348 & $\mathrm{C}=\mathrm{C}$ stretch (aromatic; $1450-1650 \mathrm{~cm}^{-1}$ ) & 1456 & 1460 \\
\hline & 1388 & 1380 & & 1544 & 1540 \\
\hline & 1407 & 1408 & & 1612 & \\
\hline \multirow[t]{2}{*}{$\mathrm{C}=\mathrm{C}$ stretch (aromatic; $1450-1650 \mathrm{~cm}^{-1}$ ) } & 1447 & 1441 & & 1708 & \\
\hline & 1626 & 1640 & C-H stretch aliphatic $\left(2850-2960 \mathrm{~cm}^{-1}\right)$ & 2855 & 2852 \\
\hline \multirow[t]{4}{*}{$\mathrm{C}=\mathrm{O}$ stretch internal conjugation } & 1709 & 1712 & & 2960 & \\
\hline & 1955 & 1948 & $\mathrm{C}-\mathrm{H}$ stretch aromatic $\left(3000-3050 \mathrm{~cm}^{-1}\right)$ & 3044 & 3042 \\
\hline & 2282 & 2270 & & & \\
\hline & 2380 & 2388 & & & \\
\hline $\mathrm{C}-\mathrm{H}$ stretch aliphatic & 2869 & 2852 & & & \\
\hline$\left(2850-2960 \mathrm{~cm}^{-1}\right)$ & 2962 & 2960 & & & \\
\hline $\mathrm{C}-\mathrm{H}$ stretch aromatic $\left(3000-3050 \mathrm{~cm}^{-1}\right)$ & 3052 & 3055 & & & \\
\hline
\end{tabular}

$\mathrm{MN}$ to the D blend indicates some deviation in the IR spectra from that of the D blend. The peak value corresponding to $\mathrm{C}-\mathrm{C}$ stretching at $872 \mathrm{~cm}^{-1}$ is observed in the $\mathrm{N}$ blend. This peak position represents a positive shift with respect to the corresponding band in PP-cp B 220 $\mathrm{MN}$ and a negative shift with respect to the corresponding band in the D blend. Similarly, the peak position $1091 \mathrm{~cm}^{-1}$ of the $\mathrm{N}$ blend in this range represents a negative shift with respect to the peak at $1103 \mathrm{~cm}^{-1}$ of the $\mathrm{D}$ blend. The peak corresponding to the $\mathrm{C}-\mathrm{O}$ stretching of ester, $\mathrm{C}=\mathrm{C}$ stretching (aromatic), characteristic $\mathrm{C}=\mathrm{O}$ stretching of ester, $\mathrm{C}-\mathrm{H}$ aliphatic and aromatic stretching was identified in both modified systems using PP-cp B $220 \mathrm{MN}$. Moreover, the addition of PP-cp B $220 \mathrm{MN}$ is confirmed by the existence of peaks at 2832 and $2844 \mathrm{~cm}^{-1}$ in the IR spectrum of EPDM. Additional peaks are observed at 793,1236,1360,1544, 1708 and $2000 \mathrm{~cm}^{-1}$ in the $\mathrm{N}$ blend and 1238, 1540, 2005 and $2844 \mathrm{~cm}^{-1}$ in the P blend. Copolymerization of the $\mathrm{D}$ blend with impact modifier is strongly indicated by these results, and the co-polymerization of the modified blend could have resulted in the modification of the blend's molecular structure, as evidenced by the presence of additional peaks.

\section{Thermal studies of impact modified blends}

The differential scanning calorimetry thermographs of the blends are shown in Figure 6. The glass transition temperatures of the immiscible systems of amorphous and crystalline polymers approach each other but do not coincide. ${ }^{19}$ The glass transition phenomenon is not evident in all of the blends featuring impact modifiers for the scan procedure adopted in this study, and only a very weak indication is observed in the $\mathrm{P}$ blend, which might be due to the effect of the $\mathrm{D}$ blend.

The reported glass transition temperatures of the various elastomers are all in the range of -20 to $-90{ }^{\circ} \mathrm{C}^{20,21}$ and all the thermographs of the blends are indicative of glass transition temperatures well below

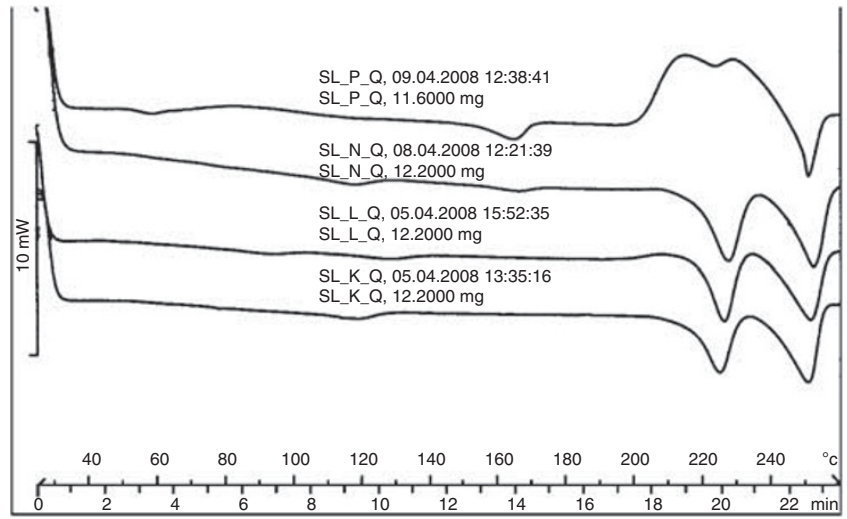

Figure 6 Differential scanning calorimetry thermographs of impact modified blends.

room temperature. Thus, glass transition temperatures below room temperature define the domains of the elastomers. The thermal data for the constituent materials and the modified blends are depicted in tabular form in Table 7.

Two endothermic melting peaks are revealed in the modified blends using impact modifiers. Co-continuity in the solidification of the PET and PBT phases of these blends might have resulted in the appearance of the two separate peaks in the thermographs. Besides these endotherms, weak and broad endothermic peaks at 118 and $124^{\circ} \mathrm{C}$ are seen in the $\mathrm{K}$ and L blends featuring Elvaloy AC. Modification of the molecular structure and/or formation of a complex structure due to the reaction of PET/PBT with the highly polar acrylate moiety of Elvaloy AC might be responsible for the endothermic peaks observed 
in thermal study. Blends using PP-cp as an impact modifier show an additional endotherm at $164{ }^{\circ} \mathrm{C}$ for the $\mathrm{N}$ blend and $161{ }^{\circ} \mathrm{C}$ for the $\mathrm{P}$ blend, which correspond to the PP-cp endotherm. Notably, similarly weak endotherms at $118^{\circ} \mathrm{C}$ in all of the blends except the $\mathrm{P}$ blend and

Table 7 Thermal data of the constituent materials of the impact modified blends

\begin{tabular}{lcccc}
\hline & & & \multicolumn{2}{c}{ Melting temperature $\left(\mathrm{T}_{m}{ }^{\circ} \mathrm{C}\right)$} \\
\cline { 4 - 5 } S. no. & $\begin{array}{c}\text { Blend constituents } \\
\text { and modified blends }\end{array}$ & $\begin{array}{c}\text { Glass transition } \\
\text { temperature }\left(\mathrm{T}_{g}{ }^{\circ} \mathrm{C}\right)\end{array}$ & $T_{\mathrm{m} 1}$ & $T_{\mathrm{m}}{ }^{2}$ \\
\hline 1 & D blend & 71 & 219 & 247 \\
2 & Elvaloy AC & - & & 94 \\
3 & PP-cp & - & & 168 \\
4 & $\mathrm{~K}$ & - & 224 & 256 \\
5 & $\mathrm{~L}$ & - & 225 & 250 \\
6 & $\mathrm{~N}$ & - & 226 & 251 \\
7 & $\mathrm{P}$ & - & 216 & 247 \\
\hline
\end{tabular}

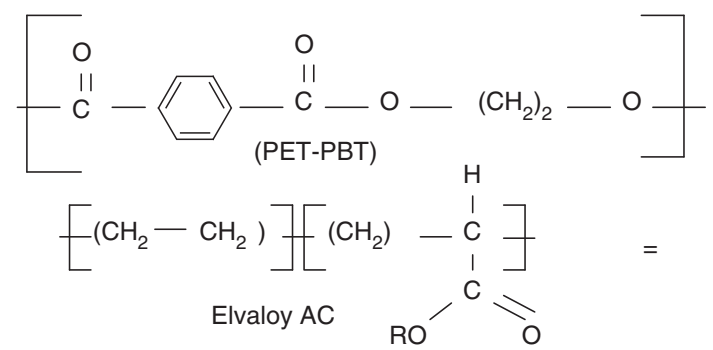<smiles>CCOC(=O)c1ccc(C(=O)CCCOC(=O)OC(C)(CC)CC)cc1</smiles>

Possible cross linking and complex formation

Figure 7 Possible reaction in the impact modified blend using Elvaloy AC. at $158^{\circ} \mathrm{C}$ are observed, which may be due to fragmentation of the molecular chains. The presence of separate endothermic melting peaks in all of the blends supports the existence of evenly distributed particles, which may be correlated with the morphological features, that is, the existence of the immiscible phases, of the blends. The broad endotherms also support the formation of a complex molecular structure.

\section{Conclusion}

- The cumulative effect of property enhancement due to blending and the use of impact modifiers as additives in the blends were established in this study using Elvaloy AC and PP-cp.

- The effect of Elvaloy $\mathrm{AC}$ as an impact modifier was more pronounced than that of PP-cp.

- A linear increment in the impact strength from about $25-160 \%$ was observed in the study using Elvaloy AC for impact modification, and the highest impact resistance was observed for the $\mathrm{L}$ blend (increment by 163\%). This was attributed to the formation of a three-dimensional network.

- A good combination of toughness and tensile strength was observed for the $\mathrm{N}$ and $\mathrm{P}$ blends using PP-cp B220MN as an impact modifier.

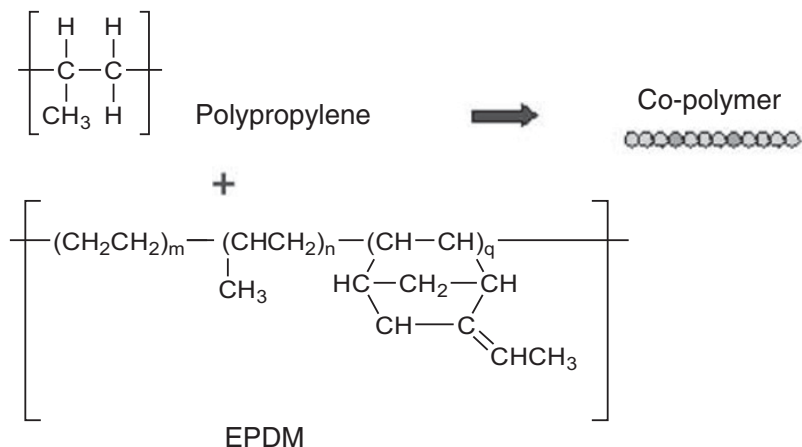

Figure 8 Possible structure of the B 220MN PP-cp. A full color version of this figure is available at Polymer Journal online.

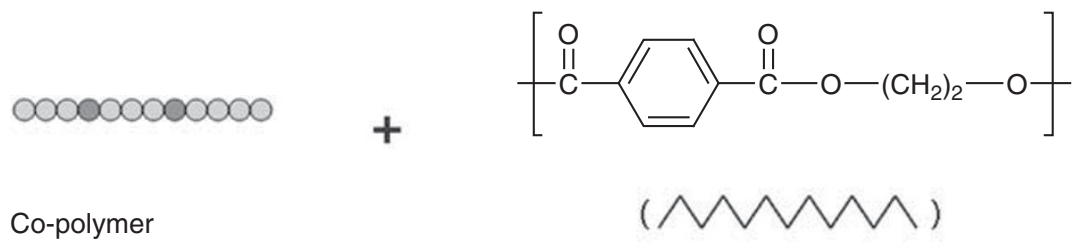

Poly(ethylene Terephthalate / matrix)
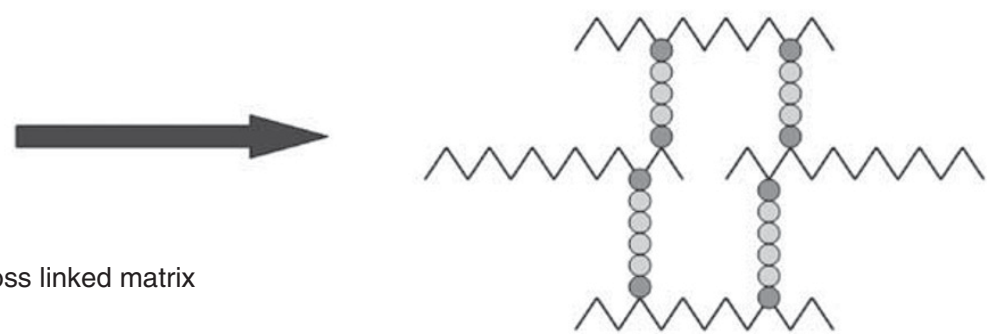

Figure 9 Possible reactions and cross linking of the polyester matrix with B 220MN PP-cp. A full color version of this figure is available at Polymer Journal online. 
- The reinforcement and network formation of the toughening additives was observed by SEM imaging; these features are responsible for the highest observed impact modification of the $\mathrm{L}$ blend using Elvaloy AC.

- FTIR analysis of the impact modified blend shows the characteristic peak positions of the different organic bonds of the macromolecules. The extra peaks and shifts in the IR peaks from the characteristic peak positions clearly indicate the complexity and modification of the molecular structure, especially at the highly polar sites (COO) of the acrylate. On the basis of the above observations, the reaction that is most likely when using Elvaloy $\mathrm{AC}$ can be predicted as shown in Figure 7.

On the basis of the results related to the use of PP-cp, it can be predicted that B220 MN PP-cp may be the co-polymer of EPDM. A diagrammatic representation of B 220MN PP-cp is shown in Figure 8.

This dipole bonding is not as strong as hydrogen bonding. Dipoledipole bonding of the polyester and $\mathrm{C}-\mathrm{H}$ group of EPDM, therefore, may lead to a strong physical interaction as shown in the Figure 9, which results in cross linking of the macromolecule.

\section{CONFLICT OF INTEREST}

The authors declare no conflict of interest.

\section{ACKNOWLEDGEMENTS}

We express our sincere gratitude to the Visvesvaraya National Institute of Technology, Nagpur (India), for providing fellowship and research facilities. We also gratefully acknowledge the technical support provided by SJS Plastiblends (P) Limited, Aurangabad (India) an ISO/TS 16949 and BVQI-certified industry.
1 Mishra, S. \& Deopura, B. Theoretical predictions of compatibility of poly (ethylene terephthalate) and poly (butylenes terephthalate) blends. Pol. Comm. 1, 26-35 (1985).

2 Aravinthan, G. \& Kale, D. Blends of poly (ethylene terephthalate) and poly(butylenes terephthalate. J. Applied Pol. Sci. 98, 75-82 (2005).

3 Supaphol, P. Thermal, crystallization, mechanical and rheological characteristics of poly (trimethylene terephthalate)/poly (ethylene terephthalate) blends. J. Pol. Sci. 12, 675-681 (2004).

4 Kuo, Y. Miscibility in two blends of homologous semicrystalline aryl polyesters involving poly (trimethylene terephthalate). Pol. J. 35, 236-243 (2003).

5 Dabgseetyb, B. Thermal, crystallization and rheological characteristics of poly (trimethylene terephthalate)/poly (butylenes terephthalate) blends. Pol. Testing 23, 187-195 (2004).

6 Woo, E. \& Lee, L. T. A novel quarternary blend of poly(ethylene terephthalate) poly (trimethylene terephthalate), poly (butylenes terephthalate). Pol. Bull. 50, 33-40 (2003).

7 Stribeck, N., Fakirov, S., Apostolov, A., Denchev, Z. \& Gehrke, R. Deformation behavior of PET, PBT and PBT-based thermoplastic elastomer as revealed by SAXS from synchrotron. Macro. Che. Phy. 204, 1000-1009 (2003).

8 Choudhary, K. \& Kale, D. Impact modification of waste pet by polyolefinic elastomer. Pol. Int. 52, 291-301 (2003).

9 Chiu, H. Impact-modified poly(ethylene terephthalate)/polyethylene-octene elastomer blends. J. Pol. Res. 12, 355-362 (2005).

10 Loyens, W. \& Groeninckx, G. Deformation mechanisms in rubber toughened semicrystalline poly(ethylene terephthalate). Polymer 44, 4929-4932 (2003).

11 Baxi, R., Peshwe, D. \& Pathak, U. Thermal studies of PET-PBT blends. NMD ATM 15-17 (2007).

12 Sperling, L. H. Physical Polymer Science 483, (Wiley publication, Ontario, Canada, 2003).

13 Braun, D. Polymer Synthesis: Theory and Practices, Ch. 4, 145-156 (Springer, New York, NY, USA, 1998).

14 Young, R. J. Comphrensive Polymer Science, 2 (UMIST, Manchester).

15 Paul, S. \& Kale, D. Impact modification of polypropylene copolymer with a polyolefinic elastomer. J. App. Pol. Sci. 76, 1480-1491 (2000).

16 Mark, H. F. Encyclopedia of Polymer Science and Technology 2 598-621 (Wiley, Hoboken, NJ, USA, 2005).

17 Dawande, S. Introduction to Polymer Science and Technology 105-162 (Denett \& Co., 2006).

18 Ullaman's Encyclopedia of Industrial Chemistry 28, VI edition, (Wiley, Weinheim, Germany, 2004.).

$19 \mathrm{Su}, \mathrm{C}$. Determination of interactions between aryl polyesters and PEI via Tg of separated phases in immiscible blends. Colloid Pol. Sci. 284, 66-73 (2005).

20 Low Temperature DSC and TMA of PBT, TA Application 3107 (M. Toledo, Columbus, OH, USA, 2006)

21 Richardson, S. Polymer Science, /590-623 (Pergamon Press, Kidlington, Oxford, 1989). 